\title{
Síntesis de la jurisprudencia casacional sobre Empleo Público más significativa del año 2020
}

\section{Summary of the cassation jurisprudence on Public Employment with higher significance for the year 2020}

\author{
José Ramón Chaves García \\ Ministerio de Justicia (España) \\ ORCID: http://orcid.org/0000-0003-3886-1642 \\ kontencioso@gmail.com
}

\section{NOTA BIOGRÁFICA}

Magistrado especialista de lo contencioso-administrativo en el Tribunal Superior de Justicia en Asturias. Doctor en Derecho y miembro numerario de la Real Academia de Jurisprudencia y Legislación. Ha sido profesor asociado de Derecho comunitario y Director General de Universidades e Investigación del Principado de Asturias.

Juan José Rastrollo Suárez

Universidad de Salamanca (España)

ORCID: https://orcid.org/0000-0003-0521-1045

rastrollo@usal.es

\section{NOTA BIOGRÁFICA}

Profesor contratado doctor (acreditado titular) de Derecho administrativo en la Facultad de Derecho de la Universidad de Salamanca. Doctor Europeus en Derecho (Universidades de Salamanca y Coimbra) con premio extraordinario de grado y doctorado. Sus principales líneas de investigación son la contratación pública, el urbanismo y el empleo público.

\section{RESUMEN}

A lo largo de la presente sección presentamos una síntesis de la jurisprudencia casacional sobre Empleo Público más significativa del año 2020.

\section{PALABRAS CLAVE}

Jurisprudencia casacional; empleo público; 2020.

\section{ABSTRACT}

Throughout the present section, we introduce a summary of cassation jurisprudence on Public Employment with higher significance for the year 2020.

\section{KEYWORDS}

Cassation jurisprudence; public employment; 2020. 
DA. Nueva Época - N. ${ }^{\circ}$ 7, enero-diciembre 2020 - ISSN: 1989-8983 - DOI: https://doi.org/10.24965/da.i7.10895 - [Págs. 156-166]

Síntesis de la jurisprudencia casacional sobre Empleo Público más significativa del año 2020 José Ramón Chaves García / Juan José Rastrollo Suárez

\begin{abstract}
SUMARIO
STS 4 DE DICIEMBRE DE 2020 (REC. 5635/2018) / STS DE 3 DE DICIEMBRE DE 2020 (REC. 1809/2019), CITANDO PRECEDENTES IDÉNTICOS / STS DE 30 DE NOVIEMBRE DE 2020 (REC. 7960/2018) / STS DE 23 DE NOVIEMBRE DE 2020 (REC. 5347/2018), CITANDO PRECEDENTES IDÉNTICOS / STS DE 19 DE NOVIEMBRE DE 2020 (REC. 5747/2018)/STS DEL 17 DE NOVIEMBRE DE 2020 (REC. 4641/2018) / STS DE 5 DE NOVIEMBRE DE 2020 (REC. 5229/2018) / STS DE 4 DE NOVIEMBRE DE 2020 (REC. 3721/2018) / STS 4 DE NOVIEMBRE DE 2020 (REC. 1198/2019) / STS DEL 21 DE OCTUBRE DE 2020 (REC. 4300/2018) / STS DEL 21 DE OCTUBRE DE 2020 (REC. 7114/2018), CITANDO PRECEDENTES IDÉNTICOS / STS DE 14 DE OCTUBRE DE 2020 (REC. 6333/2018) / STS DEL 8 DE OCTUBRE DE 2020 (REC. 2135/2018) / STS DE 28 DE SEPTIEMBRE DE 2020 (REC. 6137/2017) / STS DE 21 DE JULIO DE 2020 (REC. 2616/2019) / STS DE 14 DE JULIO DE 2020 (REC. 1187/2018), ClTANDO PRECEDENTES IDÉNTICOS / STS DE 2 DE JULIO DE 2020 (REC. 2053/2018) / STS DE 8 DE JUNIO DE 2020 (REC. 6199/2017) / STS DE 28 DE MAYO DE 2020 (REC. 4753/2018), CITANDO PRECEDENTES IDÉNTICOS / STS DE 28 DE MAYO DE 2020 (REC. 5298/2017) / STS DE 2 DE MARZO DE 2020 (REC. 3247/2019) / STS DE 10 DE FEBRERO DE 2020 (REC. 4167/2017), CITANDO PRECEDENTES IDÉNTICOS / STS DE 20 DE ENERO DE 2020 (REC. 2677/2017).
\end{abstract}

\title{
STS 4 DE DICIEMBRE DE 2020 (REC. 5635/2018)
}

CUESTIÓN.- Se centra en la interpretación que ha de otorgarse al artículo 76 del actual Texto Refundido del Estatuto Básico del Empleado Público. Más concretamente, si para el ingreso por el sistema general de acceso libre en la Escala de Técnicos Facultativos Superiores de Organismos Autónomos del Ministerio de Fomento, resulta suficiente estar en posesión o cumplir los requisitos necesarios para obtener el Título de Doctor, Licenciado, Ingeniero, Arquitecto o Grado a la fecha de finalización del plazo de presentación de instancias, o si es necesaria la obtención del título del Máster que habilita para el ejercicio de la profesión regulada de Ingeniero de Caminos, Canales y Puertos.

FUNDAMENTO.- No cabe considerar bastante esa razón para estimar suficiente la titulación de grado para acceder al Cuerpo de Ingenieros Industriales del Estado. Los niveles de formación que acreditan los títulos universitarios no pueden ser distintos según se trate de acceder al empleo público, en las condiciones de este caso, o del ejercicio privado de la profesión. Esa solución no parece aceptable desde los principios que proclama el artículo 103.1 y 3 de la Constitución que, más bien apuntan a que, cuando menos sean las mismas, sin perjuicio de que en los procesos selectivos se escoja a quienes, poseyendo esa titulación, demuestren mayor mérito y capacidad.

DOCTRINA.- Para el ingreso por el sistema general de acceso libre en la Escala de Técnicos Facultativos Superiores de Organismos Autónomos del Ministerio de Fomento, es necesario el Máster habilitante para el ejercicio de la profesión regulada de Ingeniero de Caminos, Canales y Puertos.

\section{STS DE 3 DE DICIEMBRE DE 2020 (REC. 1809/2019), CITANDO PRECEDENTES IDÉNTICOS}

CUESTIÓN.- Si un funcionario docente interino cesado el 30 de junio y readmitido al inicio del curso escolar tiene derecho a percibir retribuciones por este periodo cuando (i) ni existe norma, pacto o acuerdo que así lo reconozca, y (ii) ha aceptado el cese por no haberlo recurrido en tiempo y forma.

El supuesto planteado se analizó teniendo en cuenta lo establecido por la Cláusula 4, punto 1 de la Directiva 70/1999 de 28 de junio relativa al Acuerdo Marco de la CES, la UNICE y el CEEP sobre el trabajo de duración determinada de acuerdo con la reciente STJUE de 21 de noviembre de 2018, asunto C-245/17, así como la sentencia del Tribunal Supremo de 11-06-2018, RC 3765/2015.

FUNDAMENTO.- No existe discriminación respecto de otros funcionarios interinos de ejercicios anteriores, pues el principio de no discriminación se ha aplicado y se ha concretado mediante el Acuerdo Marco únicamente en lo que respecta a las diferencias de trato entre trabajadores con contrato de duración determinada y trabajadores con contrato por tiempo indefinido que se encuentren en una situación comparable. Además, no se trata de vacantes específicas sino de nombramientos como interinos para acceso a esa condición y no para un centro determinado, de manera que lo relevante es que la relación de servicio había sido extinguida válidamente al final del periodo lectivo de cada curso escolar, sobre la base de razones objetivas y predeterminadas, concretamente por razones organizativas. 
DOCTRINA.- la finalización del vínculo de relación de servicio se produce en las respectivas fechas de los ceses del personal funcionario interino -en este caso a 30 de junio de cada uno de los años reclamadosy la iniciación de un nueva relación de servicio al inicio del siguiente curso escolar, con lo que no invalida los efectos jurídicos de cada uno de los ceses precedentes. Por ende, no otorga derecho alguno al funcionario interino en esta situación para percibir retribuciones por el periodo de tiempo transcurrido entre el cese anterior y el inicio de una nueva relación de servicio. Tampoco otorga derecho al reconocimiento de otros efectos de índole administrativa, como antigüedad o cómputo de servicios prestados, en relación al indicado periodo.

\section{STS DE 30 DE NOVIEMBRE DE 2020 (REC. 7960/2018)}

CUESTION.- Si la cuantía a efectos procesales del objeto litigioso cuando la pretensión es formulada por un sindicato o cualquier entidad en representación de intereses colectivos, ha de determinarse en atención al conjunto de intereses colectivos que representa, o si procede cuantificarla de forma individualizada según el daño ocasionado a cada afiliado o representado o, en sí, si debe considerarse de cuantía indeterminada.

FUNDAMENTO.- No hay en la norma legal, art. 42 LJCA, un trato específico para acciones ejercitadas por una organización sindical o cualquier otra entidad que represente intereses colectivos en que estén en juego derechos fundamentales como el de igualdad de trato.

Un supuesto como el de autos presenta, por tanto, la particularidad de que, independientemente de la cuantificación económica de la segunda pretensión, no clarificada en su exacta cuantía, está en discusión la aplicación o no del principio de igualdad de trato como eje principal y necesario para resolver aquella. De prosperar la invocación del principio de igualdad de trato, lo que aquí aconteció, se abre la vía para declarar los derechos económicos. En consecuencia, en las circunstancias del caso debemos entender que se trata de un recurso de cuantía indeterminada.

DOCTRINA.- Por tanto, la respuesta la cuestión de interés casacional es que cuando una organización sindical o cualquier otra entidad en representación de intereses colectivos formule una pretensión engarzada con principios o derechos fundamentales de la Constitución o del Derecho de la Unión Europea que se reclaman para un colectivo o conjunto, aunque también lleve aparejada una pretensión económica, prevalece la cuantía indeterminada de la primera pretensión.

\section{STS DE 23 DE NOVIEMBRE DE 2020 (REC. 5347/2018), CITANDO PRECEDENTES IDÉNTICOS}

CUESTION.- (Si) resulta procedente reconocer al personal estatutario interino una indemnización de 20 días de salario por año de servicio, por entender que se ha producido una utilización abusiva de los nombramientos de dicho personal estatutario interino de los servicios de salud.

FUNDAMENTO.- La inaplicación de tal doctrina con base en que la situación jurídico-laboral del Sr. Losada Rodríguez era diferente a la de la persona afectada por esa sentencia del Tribunal Europeo pues no concurría un supuesto de sucesivos contratos o relaciones laborales, sino que se trataba de una única vinculación funcionarial,

DOCTRINA.- El cese de un funcionario interino, con una relación de servicios prolongada durante siete años y una previa de pocos meses, no determina derecho a indemnización de 20 días por año de trabajo desempeñado previsto en la legislación laboral y no en la legislación funcionarial.

\section{STS DE 19 DE NOVIEMBRE DE 2020 (REC. 5747/2018)}

CUESTIÓN.- Si se ha producido o no, en el caso examinado, una utilización abusiva de los nombramientos de personal estatutario eventual ex artículo 9.3 Estatuto Marco del Personal Estatutario, de conformidad con la Sentencia del Tribunal de Justicia de 14 de septiembre de 2016 (asuntos acumulados C-184/15 y C-197/15 ). Determinar, en su caso, las consecuencias, laborales y/o económicas, que se anudan en dicha declaración de abuso.

FUNDAMENTO.- El nombramiento de interinidad implica que el desempeño de una plaza vacante cuando sea necesario atender las funciones propias del puesto hasta que se incorpore el titular o se amortice la plaza. Se está ante un nombramiento continuado y no un encadenamiento de «sucesivos contratos o rela- 
ciones laborales de duración determinada», a los que alude la cláusula 5.1 del Acuerdo marco, luego no hay abuso si el cese se produce en las circunstancias antes expuestas [...] las anteriores circunstancias implican que no se incurriese en abuso, en los términos que previene el Acuerdo marco, pues el nombramiento y las prórrogas fueron por motivos temporales o coyunturales en tanto se creaba la vacante estructural, como así se hizo.

DOCTRINA.- Se rechaza identificar que hubiere abuso por su nombramiento como interina una vez creada la plaza por vacante estructural, alegando -como sostiene doña Belén- que en caso de cese estaría desprotegida pues no sería indemnizada como indefinida no fija. Aparte de que esta Sala ha rechazado convertir el estatus profesional de un trabajador estatutario eventual en indefinida no fijo por prestar servicios encadenando prórrogas, se habrían dado los pasos previstos en las sentencias 1425 y 1426/2018 con la creación de vacante estructural, su cobertura en forma ordinaria y, entre tanto, sirviéndola como interina. El cese por cubrirse la plaza con un titular será la consecuencia lógica ligada a la condición de interino.

\section{STS DEL 17 DE NOVIEMBRE DE 2020 (REC. 4641/2018)}

CUESTIÓN.- Si la carrera profesional horizontal ha de ser considerada dentro del ámbito de las «condiciones de trabajo» a efectos de valorar las diferencias de régimen jurídico aplicables a los funcionarios interinos y al personal laboral no fijo y, en su caso, determinar si existe o no discriminación en aquellos supuestos en que dicho personal quede excluido de la posibilidad de realizar dicha carrera horizontal.

FUNDAMENTO.- En la STS de 28 de mayo de 2020 (rec. 4753/2018) [...] y, antes, en la sentencia de la antigua Sección Séptima de 30 de junio de 2014 (casación n. ${ }^{\circ}$ 1846/2013), que la carrera profesional horizontal forma parte de las condiciones de trabajo a que se refiere la cláusula $4 .^{\text {a }}$ del Acuerdo Marco anexo a la Directiva 1999/70/CE y que carece de justificación objetiva negar el derecho a ella al personal vinculado con la Administración por tiempo determinado que realiza las mismas funciones que el fijo de categoría comparable al que sí se le reconoce.

DOCTRINA.- No haber cuantificado la cantidad procedente a que ascenderían las retribuciones a percibir por el Sr. Iván no impide el reconocimiento de su derecho a la carrera profesional horizontal y al complemento de carrera porque se traducen en magnitudes determinables en ejecución de sentencia.

\section{STS DE 5 DE NOVIEMBRE DE 2020 (REC. 5229/2018)}

CUESTIÓN.- Si, en los procesos selectivos de acceso al empleo público, resulta compatible con los límites de la discrecionalidad técnica del órgano de selección y el principio de seguridad jurídica, el establecimiento de pruebas que tuvieran por objeto el desarrollo escrito de temas de carácter general que estuvieran relacionados, aunque no fueran coincidentes, con los enunciados concretos del programa de la convocatoria.

FUNDAMENTO.- Se diseñe como se diseñe el ejercicio teórico el aspirante debe tener la certeza de que son esas y no otras las materias cuyo conocimiento debe demostrar. La seguridad jurídica del proceso selectivo pasa también por saber a qué atenerse en cuanto a qué conocimientos debe demostrar en un proceso en el que se juega su esfuerzo y futuro profesional. El carácter vinculante del temario no va en detrimento de la discrecionalidad técnica de los tribunales calificadores.

DOCTRINA.- Un sistema de oposición en el que se prevé un temario que relaciona los contenidos teóricos de inexcusable demostración por el aspirante, el tema o temas que sean objeto de exposición deben responder a los enunciados y contenido del temario o programa. Es, por tanto, contrario a la seguridad jurídica del proceso selectivo que se apodere al tribunal calificador para que fije como temas objeto de exposición otros no expresamente previstos en el temario, aun relacionados con él, quedando ese temario no como la pauta de los conocimientos teóricos que deben demostrarse sino como referencia.

\section{STS DE 4 DE NOVIEMBRE DE 2020 (REC. 3721/2018)}

CUESTIÓN.- Si al personal al servicio de la Administración Pública liberado sindical que presta servicios en desarrollo de su actividad sindical le resulta o no de aplicación la normativa sobre incompatibilidades del personal al servicio de las Administraciones Públicas, y más, concretamente, el artículo 16.4 de la Ley 
53/1994, 26 de diciembre, Incompatibilidades del Personal de las Administraciones Públicas cuando desempeña labores de asesoramiento jurídico al sindicato y sus afiliados.

FUNDAMENTO.- La Sra. Carlota dedica la totalidad de su jornada a la actividad sindical. Esa actividad consiste en el asesoramiento jurídico, tanto extraprocesal como procesal, a AFAPNA y a sus afiliados. Es una actividad que no realiza en provecho propio mediante una remuneración satisfecha por los asesorados o por el sindicato, ni se extiende a cuestiones ajenas a las propiamente laborales y sindicales, ni a sujetos distintos de AFAPNA y de sus miembros en esas exclusivas materias. No es, pues, la actividad privada que contempla el artículo 16.4 de la Ley 53/1984. Es, por el contrario, una actividad que, en sí misma, no está vedada al sindicato ni prohibida su realización por empleados públicos que no perciban el complemento específico igual o superior al $30 \%$ del sueldo base.

DOCTRINA.- Recordando, además, la relevancia constitucional de la acción sindical, no cabe considerar incompatible una actuación como la de la Sra. Carlota ni, por tanto, imputar a la sentencia de apelación las infracciones que le ha atribuido el escrito de interposición. [...] No es una segunda actividad suya sino la única que ha cambiado de naturaleza por su condición de liberada sindical, la cual, además, no le priva del derecho a percibir los complementos retributivos asignados a su puesto de trabajo.

\section{STS 4 DE NOVIEMBRE DE 2020 (REC. 1198/2019)}

CUESTIÓN.- Si los funcionarios de Cuerpos estatales docentes no universitarios, pertenecientes en origen a la Administración General del Estado (Ministerio de Educación) pero transferidos a las Comunidades Autónomas, tienen derecho a ser considerados como funcionarios en activo en la Administración General del Estado; o si, por el contrario, a estos funcionarios estatales transferidos no cabe reconocerles tales derechos del ámbito de la Administración General del Estado, sino los que se establezcan por la legislación autonómica.

FUNDAMENTO.- Su condición, por tanto, es la de funcionaria de un cuerpo docente que la legislación educativa (disposición adicional sexta de la Ley Orgánica 2/2006 de Educación) estructura como un cuerpo estatal, [...] Esta vinculación a la legislación estatal de la administración en la que se reingresa esta formulada explícitamente también en el art. 87.3 TREBEP. Por consiguiente, no es de aplicación a la actora, que está integrada en el servicio activo en la Administración de la Comunidad Autónoma de Galicia, una norma del ámbito específico de la legislación de función pública del Estado como es el art. 33.2 de la Ley 31/1990.

DOCTRINA.- El régimen normativo de consolidación del grado y conjunto de complementos que corresponde a los funcionarios de cuerpos docentes no universitarios integrados en una administración autonómica, con ocasión de su reintegro a la situación de servicio activo desde la de servicios especiales por desempeño de los cargos previstos en el art. 87.3 del TREBEP, se rige por la legislación de la Administración autonómica a que se reintegran en servicio activo, sin que resulte de aplicación la legislación de función pública estatal prevista para la Administración General del Estado, ni, en particular, el art. 33.2 de la Ley 31/1990, de 27 de diciembre, de Presupuestos Generales del Estado.

\section{STS DEL 21 DE OCTUBRE DE 2020 (REC. 4300/2018)}

CUESTIÓN.- Determinar si los funcionarios que se encuentran prestando servicios en otra Administración Pública distinta a la de origen, tienen derecho a participar por el turno de promoción interna, en los procesos selectivos convocados por su Administración de origen, sin necesidad de solicitar el reingreso en la misma.

FUNDAMENTO.- En definitiva, lo que garantiza el art. 88.3 TREBEP a los funcionarios en situación de servicio activo en otra Administración Pública, cuando se encuentren en dicha situación por haber obtenido un puesto de trabajo mediante los sistemas de provisión previstos en este Estatuto es el acceso a los procedimientos de provisión de puestos de trabajo.

DOCTRINA.- En definitiva, y ciñendo nuestra doctrina al específico supuesto de los funcionarios en situación de servicio activo, que es el caso que enjuiciamos, hemos de declarar que la aplicación de régimen establecido en el art. 88.3 del EBAP no otorga el derecho a participar en procedimientos de promoción interna convocados por su Administración de origen a los funcionarios en servicio activo en otra Administración pública que se encuentre en esta situación por haber obtenido puestos en la misma por procedimientos de 
provisión previstos en el EBEP. Todo ello sin perjuicio de que tal derecho pudiera ser otorgado por la legislación de función pública propia de cada Administración pública, pues el EBEP establece un marco mínimo común pero no excluye otras medidas que potencien, ampliando su ámbito, la participación en la promoción interna (art. 18.3 y 4 EBEP).

\section{STS DEL 21 DE OCTUBRE DE 2020 (REC. 7114/2018), CITANDO PRECEDENTES IDÉNTICOS}

CUESTIÓN.- Si el desempeño por un funcionario perteneciente al Cuerpo de la Guardia Civil de un puesto de trabajo de jefatura de unidad, de manera accidental y por sustitución, ha de conllevar o no la percepción de la totalidad de los complementos de destino y específico (en sus componentes general y singular) del puesto que, como mando, desempeña.

FUNDAMENTO.- Así, pues, mientras que ningún reproche parece suscitar que un ejercicio puntual de funciones de otro puesto no comporte el derecho a percibir las retribuciones complementarias de este último, tal como dicen esos artículos, solución diferente ha de darse cuando del ejercicio continuado de las funciones esenciales de ese ulterior puesto se trata. Mientras que el primero no suscita dudas de que cae bajo las previsiones de los preceptos presupuestarios, el segundo caso, contemplado desde el prisma de la igualdad, conduce al reconocimiento del derecho del funcionario en cuestión a las retribuciones complementarias del puesto que ejerce verdaderamente con el consentimiento de la Administración.

DOCTRINA.- Ha de interpretarse el artículo 26. Uno D), párrafo segundo, de la Ley 17/2012 -y los artículos de las Leyes de Presupuestos Generales del Estado posteriores que lo han reproducido y relaciona el auto de admisión- en el sentido de que no impide que los funcionarios que desempeñen la totalidad o las tareas esenciales de un puesto de trabajo distinto de aquél para el que fueron nombrados perciban las diferencias retributivas entre los complementos de destino y específico del puesto efectivamente desempeñado y los del suyo.

\section{STS DE 14 DE OCTUBRE DE 2020 (REC. 6333/2018)}

CUESTIÓN.- Si puede declararse a los funcionarios interinos en situación de servicios especiales y, en caso afirmativo, si cabe computar en un proceso selectivo -con carácter general y sin adentrarse en el contenido de las funciones efectivamente desempeñadas- el tiempo transcurrido en dicha situación como experiencia profesional equivalente a las funciones propias de la categoría a que se concurre.

FUNDAMENTO.- Por consiguiente, la interpretación del art. 10.5 del Estatuto Básico del Empleado Público, aprobado por Ley 7/2007, de 12 de abril, del Estatuto Básico del Empleado Público que dispone que «5. A los funcionarios interinos les será aplicable, en cuanto sea adecuado a la naturaleza de su condición, el régimen general de los funcionarios de carrera» debe realizarse en los términos que equiparan la concesión y alcance de la situación de servicios especiales a los funcionarios interinos y, por ende, al personal estatutario interino, puesto que, según declara la citada sentencia del TJUE de 20 de diciembre de 2017 «La cláusula 4 del Acuerdo marco sobre el trabajo de duración determinada, que figura en el anexo de la Directiva 1999/70, debe interpretarse en el sentido de que se opone a una norma nacional, como la controvertida en el litigio principal, que excluye de manera absoluta la concesión a un trabajador con contrato de duración determinada, a efectos de desempeñar un cargo político representativo, de un permiso en virtud del cual la relación de trabajo se suspende hasta la reincorporación de este trabajador al dejar de desempeñar el mencionado cargo, mientras que reconoce este derecho a los trabajadores fijos».

DOCTRINA.- Sí puede declararse a los funcionarios interinos en situación de servicios especiales en los casos previstos para los funcionarios de carrera en la legislación aplicable a los mismos, así como, en principio, y con carácter general, y sin adentrarnos ahora en el contenido de las funciones efectivamente desempeñadas, cuestión que debe discernirse en cada supuesto, debe computarse el tiempo transcurrido en dicha situación como experiencia profesional equivalente a las funciones propias de la categoría a que se concurre.

\section{STS DEL 8 DE OCTUBRE DE 2020 (REC. 2135/2018)}

CUESTIÓN.- Si el artículo 53 de la Ley Orgánica 3/2007, de 22 de marzo, para la igualdad efectiva de mujeres y hombres, en relación con su Disposición Adicional Primera, contiene un mandato jurídico reglado 
de tal modo que su incumplimiento puede determinar la nulidad del proceso selectivo o de alguno de los actos dictados en el mismo.

FUNDAMENTO.- No nos encontramos ante una opción que se deja a la Administración sino ante una exigencia que debe cumplir salvo que haya razones de entidad, debidamente explicadas, que lo impidan. De ahí que, de no darse estas circunstancias, la actuación contraria al principio de paridad o composición equilibrada deba suponer su invalidez pues los preceptos de esta naturaleza, despliegan, entre otros efectos, el de límite o impedimento frente a aquel proceder que contraríe el mandato por ellos establecido. Y no parece necesario recordar que el principio de igualdad forma parte del contenido que la propia Constitución considera más valioso y protege especialmente.

DOCTRINA.- El principio de composición equilibrada de mujeres y hombres del artículo 53 de la Ley Orgánica $3 / 2007$, concretado en los términos de su disposición adicional primera, es sustancialmente equivalente al del artículo 60.1 del Estatuto Básico del Empleado Público y consiste en un mandato cuyo incumplimiento puede determinar la nulidad del proceso selectivo o de alguno de sus trámites atendiendo a las particulares circunstancias de cada caso.

\section{STS DE 28 DE SEPTIEMBRE DE 2020 (REC. 6137/2017)}

CUESTION.- Si la indemnización a los policías por lesiones en acto de servicio que siguieron vía penal es un supuesto de indemnidad del funcionario o de responsabilidad patrimonial. Y para el caso de que fuera un supuesto de indemnidad, cuál es el régimen aplicable.

FUNDAMENTO.- Las disposiciones que regulan la relación estatutaria de los empleados públicos han determinado tradicionalmente, y previsto en forma expresa, que los daños y perjuicios que los agentes de los cuerpos y fuerzas de seguridad sufran en el ejercicio de la función pública, sin mediar ningún tipo de dolo o negligencia, «deben ser resarcidos por la propia Administración en virtud del principio de resarcimiento o de indemnidad, que resulta ajeno a la responsabilidad patrimonial». Y que «las normas que han previsto en forma expresa este principio se han producido, como es lógico, en relación con los agentes públicos de cualquier clase que ejercen en forma legítima la fuerza coactiva del Estado de Derecho». También, hemos considerado claro que «en caso de ausencia de una regulación legal expresa debe entrar en vigor la aplicabilidad supletoria de las normas que lo admiten en otros casos en los que existe identidad de razón».

DOCTRINA.- Procede afirmar que, en las circunstancias señaladas, las lesiones y perjuicios sufridos por los agentes de policía como consecuencia de acciones ilícitas de las personas sobre las que ejercen, sin dolo o negligencia por su parte, las funciones que son propias de su cargo deben ser resarcidos por la Administración, mediante el principio del resarcimiento o de indemnidad, principio general que rige para los empleados públicos.

\section{STS DE 21 DE JULIO DE 2020 (REC. 2616/2019)}

CUESTIÓN.- Si la cuantía que perciben los funcionarios del Cuerpo Nacional de Policía por turnicidad ha de considerarse un complemento o una gratificación a efectos retributivos y, por ello, si ha de incluirse, o no, dentro del concepto de "vacaciones anuales retribuidas», de modo que el disfrute de vacaciones no pueda acarrear una discriminación de las retribuciones que con carácter habitual viene percibiendo el funcionario.

FUNDAMENTO.- Se trata, por el contrario, de una retribución ordinaria por los servicios que se prestan regularmente, de forma habitual, por aquellos que realizan ese trabajo en la forma de «turnos rotatorios completos», los cuales perciben el correspondiente complemento todos los meses, periódicamente, salvo el de vacaciones, en el que no se realizan turnos, sencillamente porque no se realiza ninguna prestación.

DOCTRINA.- Con amparo en las sentencias del Tribunal de Justicia de la Unión Europea de 15 de septiembre de 2011 (asunto C-155/10) y de 22 de mayo de 2014 (asunto C-539/12), y los principios que de ellas se infieren, aunque se refieran al trabajador en general: «En el marco de un análisis específico, en el sentido de la jurisprudencia citada, se ha estimado que los inconvenientes intrínsecamente vinculados a la ejecución de las tareas que incumben al trabajador [...] y compensados por un importe pecuniario incluido en el cálculo de la retribución global del trabajador deben necesariamente formar parte del importe al que tiene derecho el trabajador durante sus vacaciones anuales (véase la sentencia Williams y otros, EU:C:2011:588, apartado 
24). [...] Además, el Tribunal de Justicia ha precisado que todos los componentes de la retribución global inherentes a la condición personal y profesional del trabajador deben mantenerse durante sus vacaciones anuales retribuidas. De este modo, debían mantenerse, en su caso, los complementos relacionados con su calidad de superior jerárquico, con su antigüedad y con sus cualificaciones profesionales».

\section{STS DE 14 DE JULIO DE 2020 (REC. 1187/2018), CITANDO PRECEDENTES IDÉNTICOS}

CUESTIÓN.- «[...] si el plazo máximo de seis meses de suspensión provisional de funciones que puede adoptarse como medida cautelar en la tramitación de un expediente disciplinario frente a un funcionario público a que se refiere el apartado 3 del artículo 98 del Real Decreto Legislativo 5/2015, de 30 de octubre, por el que se aprueba el texto refundido de la Ley del Estatuto Básico del Empleado Público (TREBEP) resulta también de aplicación durante la tramitación de un procedimiento judicial, o si, por el contrario, la suspensión provisional acordada por la Administración se mantendrá por todo el tiempo a que se extienda la prisión provisional u otras medidas decretadas por el Juez y que determinen la imposibilidad de desempeñar el puesto de trabajo [...]».

FUNDAMENTO.- Que la previsión del art. 8.3 de la LOFCSE, de suspensión de funciones durante toda la duración del procedimiento penal, como medida cautelar administrativa, es una especificidad del régimen de los miembros de las Fuerzas y Cuerpos de Seguridad del Estado, lo confirma lo dispuesto en el art. 33.2.c) de la Ley Orgánica 4/2010, de 20 de mayo, de Régimen Disciplinario del Cuerpo nacional de Policía, que establece también esta posibilidad de adoptar excepcionalmente tal medida y con la debida motivación. (...) Esta norma, según prevé la disposición final sexta "[...] se aplicará a los Cuerpos de Policía Local de acuerdo con lo previsto en la legislación orgánica reguladora de las Fuerzas y Cuerpos de Seguridad", por lo que supone de nuevo el reenvío a la previsión del art. 8.3 en relación con el art. 52 ambos de la LOFCSE.

DOCTRINA.- La medida cautelar de suspensión de funciones puede adoptarse por la autoridad administrativa que ostenta la competencia de dirección de la policía local (Alcalde) hasta la finalización del procedimiento penal por resolución definitiva, y aún cuando no se haya impuesto por la jurisdicción penal medida cautelar que impida la prestación de servicios, si bien respecto a los efectos económicos habrá de aplicarse la limitación establecida en la legislación específica del régimen general de funcionarios, todo ello de conformidad con los principios establecidos en el art. 8.3 en relación con el art. 52 de la LOFCSE y las disposiciones de derecho autonómico que las complementan.

\section{STS DE 2 DE JULIO DE 2020 (REC. 2053/2018)}

CUESTIÓN.- «[...] determinar cuál es el contenido del deber de motivación exigible en las resoluciones administrativas que acuerdan el cese de funcionarios públicos en puestos de libre designación».

FUNDAMENTO.- La motivación, por tanto, de los actos dictados en el ejercicio de potestades discrecionales ha de ser expresa, clara y comprensible, señalando las razones por las que debe ser cesado quien ocupaba un puesto como funcionario nombrado por el sistema de libre designación. Esta motivación se basa en una interpretación normativa, de los artículos 35.1.i) de la Ley 39/2015, y 58.1 del citado Reglamento General de ingreso de personal al servicio de la Administración General del Estado, que pretende evitar eventuales zonas de indefensión, y proscribir cualquier forma de arbitrariedad en la actuación administrativa. De manera que los titulares de los puestos de trabajo provistos por el procedimiento de libre designación con convocatoria pública puedan «ser cesados discrecionalmente» (artículo 80.4 del EBEP).

DOCTRINA.- El funcionario que ocupa un puesto de libre designación no se encuentra cubierto por la inamovilidad en el cargo, y que su cese tiene un componente de libre apreciación evidente que, no obstante, no le exime, como hemos repetido, de motivar las razones de la decisión. [...] Esta motivación ciertamente debe ir más allá de lo previsto en el artículo 58.1, párrafo segundo, del RGPPT, según el cual «la motivación de esta resolución se referirá a la competencia para adoptarla». Por tanto, al funcionario cesado debe dársele razón de por qué las razones de oportunidad, basadas en la confianza e idoneidad apreciada para el puesto y que llevaron a su elección, ya no concurren o si concurren qué otra circunstancia objetiva determina la pertinencia del cese. La razón o razones del cese no serán enjuiciables en lo que tiene de libre apreciación; ahora bien, es exigible que se explicite evitándose expresiones opacas, estandarizadas, que puedan encubrir una intención patológica por falsa, caprichosa o ajena a los requerimientos del puesto o a las exigencias de idoneidad profesional que llevaron a la elección. 


\section{STS DE 8 DE JUNIO DE 2020 (REC. 6199/2017)}

CUESTIÓN.- Si el procedimiento de revisión de oficio resulta de aplicación a aquellos supuestos en que la relación jurídica administrativa no haya sido válidamente constituida por ausencia de uno de sus elementos esenciales, como en el caso, la ausencia de titulación del personal nombrado para el desempeño de las funciones.

FUNDAMENTACIÓN.- Por ello a la vista de que el cese de la recurrente, tras el oportuno trámite de audiencia, se limita a dejar sin efecto de futuro el desempeño interino del puesto de trabajo y carece de efectos económicos y administrativos que ya se hubieran producido hasta el momento del cese se concluye que, en un caso como el de autos, no es preciso incoar un procedimiento de revisión de oficio por lo que se confirma la Sentencia del TSJ de la Comunidad Valenciana.

DOCTRINA.- El procedimiento de revisión de oficio no resulta de aplicación a aquellos supuestos en que la relación jurídica administrativa no ha sido válidamente constituida por ausencia de uno de sus elementos esenciales, como en el caso acontece, ante la ausencia de titulación habilitante para el desempeño de las funciones.

\section{STS DE 28 DE MAYO DE 2020 (REC. 4753/2018), CITANDO PRECEDENTES IDÉNTICOS}

CUESTIÓN.- Si el desempeño de un puesto de trabajo como funcionario interino puede ser computado a los efectos de progresión en la carrera horizontal una vez que el funcionario adquiere la condición de personal estatutario fijo. Y ello desde la óptica de la Directiva 1999/70/CE del Consejo, de 28 de junio de 1999, relativa al Acuerdo marco de la CES, la UNICE y el CEEP sobre el trabajo de duración determinada y la normativa nacional correspondiente.

Y precisa que los preceptos que debemos interpretar son el artículo 40 del Estatuto Marco del Personal Estatutario de los Servicios de Salud y el artículo 25.2 del Estatuto Básico del Empleado Público, en relación con la Directiva 1999/70/CE del Consejo, de 28 de junio de 1999, relativa al Acuerdo marco de la CES, la UNICE y el CEEP sobre el trabajo de duración determinada, y los artículos 9.3 y 14 de la Constitución, así como otros preceptos concordantes que resulten de aplicación.

FUNDAMENTO.- $Y$ nuestra sentencia n. ${ }^{\circ}$ 225/2020, de 18 de febrero, con cita de diversas sentencias de esta Sala y del Tribunal de Justicia, varias de ellas citadas por el escrito de interposición, no dio lugar al recurso de casación de la Administración autonómica allí concernida, con lo cual mantuvo definitivamente el pronunciamiento de apelación que le condenaba a reconocer a la recurrente su permanencia de cinco años en la categoría de entrada para el acceso a la categoría personal superior. Es decir, concluyó que el tiempo de servicios como interina debía tenerse en cuenta para la progresión en la carrera profesional.

DOCTRINA.- Conforme a la Directiva 1999/70/CE, del Consejo de 28 de junio, relativa al Acuerdo marco de la CES, la UNICE y el CEEP sobre el trabajo de duración determinada, y los preceptos citados del Estatuto Marco del Personal Estatutario y de las Leyes 16 y 44/2003, el desempeño de un puesto de trabajo como interino puede ser computado a los efectos de progresión en la carrera horizontal una vez adquirida la condición de personal estatutario fijo.

\section{STS DE 28 DE MAYO DE 2020 (REC. 5298/2017)}

CUESTIÓN.- «[...] determinar el alcance de la incompatibilidad prevista en el artículo 178.2.b) de la LOREG entre la condición de concejal de una Entidad Local con el desempeño de un puesto de trabajo de carácter temporal al servicio del Ayuntamiento».

FUNDAMENTO.- Teniendo en cuenta la regulación de las situaciones administrativas contenida en el citado TRLEBEP, y prevista, para los funcionarios públicos, en el artículo 85, y para el personal laboral en el artículo 92. Además, dicha temporalidad difícilmente podría conjugarse con la exigencia de que se trate de «personal en activo», como demanda el propio artículo 178.2.b) de tanta cita.

En definitiva, cuanto llevamos expuesto impide que podamos incluir en la expresada causa de incompatibilidad a quien desempeña un puesto de trabajo como personal laboral de carácter temporal, por 180 días, no estable, financiado con fondos ajenos al municipio, salvo que hagamos una interpretación extensiva de dicho supuesto de incompatibilidad, que, como antes adelantamos en el fundamento anterior y ahora reite- 
ramos, está proscrita en estos supuestos, según la doctrina del Tribunal Constitucional y la jurisprudencia de este Tribunal Supremo.

DOCTRINA.- Conviene insistir que en la medida en que las causas de incompatibilidad, que prevé la LOREG, constituyen excepciones a los criterios generales de participación en tareas de carácter público, han de ser interpretadas, por tal razón, de modo restringido. En este punto, además, hay que recordar que, desde luego, el régimen de incompatibilidades, con carácter general, pretende salvaguardar la objetividad e imparcialidad en el desempeño de la función pública. Sin que advirtamos ninguna colisión en este caso, a tenor de la falta de una justificación adecuada al respecto.

\section{STS DE 2 DE MARZO DE 2020 (REC. 3247/2019)}

CUESTIÓN.- Determinar si los policías locales interinos, ya nombrados, pueden portar armas de fuego.

FUNDAMENTO.- El propio Estatuto señala la equiparación en el contenido funcional y su ejercicio entre ambas clases de funcionarios, señalando el art. 10 que los funcionarios interinos son nombrados como tales para el desempeño de funciones propias de funcionarios de carrera y que les será aplicable, en cuanto sea adecuado a la naturaleza de su condición, el régimen general de los funcionarios de carrera.

DOCTRINA.- En consecuencia y desde el punto de vista estatutario el funcionario interino, en este caso policía local interino, realiza las mismas funciones que los que sean de carrera y con las mismas facultades, en este caso en relación con el uso de armas de fuego, sin que se desprenda de dicha normativa especialidad o limitación al respecto [...] ha de concluirse, respondiendo a la cuestión planteada en el auto de admisión, que los policías locales interinos, ya nombrados, pueden portar armas de fuego.

\section{STS DE 10 DE FEBRERO DE 2020 (REC. 4167/2017), CITANDO PRECEDENTES IDÉNTICOS}

CUESTIÓN.- [...] relativa a la interpretación que haya de darse al artículo 26 de la Ley 17/2012, de 27 de diciembre, de Presupuestos Generales del Estado para el año 2013, al artículo 24 de la Ley 22/2013, de 23 de diciembre, de Presupuestos Generales del Estado para el año 2014, al artículo 24 de la Ley 36/2014, de 26 de diciembre, de Presupuestos Generales del Estado para el año 2015, y al artículo 23 de la Ley 48/2015, de 29 de octubre, de Presupuestos Generales del Estado para el año 2016, concretamente:

1. Si tales preceptos deben ser interpretados en el sentido de que impiden a los funcionarios públicos que desempeñen idénticos cometidos o funciones que los asignados a un puesto distinto del que sirven a través del oportuno nombramiento percibir los complementos de destino y específico asignados a aquel puesto.

2. Si, por el contrario, dichos preceptos solo resultan de aplicación cuando el funcionario público realiza tareas concretas u ocasionales de otro puesto de trabajo, pero no la totalidad de las funciones y responsabilidades asignadas al mismo en la correspondiente Relación de Puestos de Trabajo o disposición equivalente.

FUNDAMENTO.- El mismo hecho de que se haya formado y mantenido pone de manifiesto una realidad de la Administración Pública: la existencia de supuestos en que funcionarios realizan cometidos de puestos que no son los suyos o que puestos de trabajo con el mismo contenido funcional tienen asignados complementos diferentes. Se trata, desde luego, cuando menos de una disfunción, pero es un fenómeno que se ha dado en la medida suficiente para que el Tribunal Supremo haya llegado a establecer esa doctrina.

Asimismo, debe destacarse que es una práctica imputable a la propia Administración, que es la que debe asegurar la correcta provisión de los puestos de trabajo necesarios para el cumplimiento de sus funciones y crear las condiciones en las que no exista la posibilidad o la necesidad de que funcionarios destinados en un determinado puesto realicen las tareas de otro.

DOCTRINA.- Ha de interpretarse el artículo 26. Uno D), párrafo segundo, de la Ley 17/2012 -y los artículos de las Leyes de Presupuestos Generales del Estado posteriores que lo han reproducido y relaciona el auto de admisión- en el sentido de que no impide que los funcionarios que desempeñen la totalidad o las tareas esenciales de un puesto de trabajo distinto de aquél para el que fueron nombrados perciban las diferencias retributivas entre los complementos de destino y específico del puesto efectivamente desempeñado y los del suyo. 


\section{STS DE 20 DE ENERO DE 2020 (REC. 2677/2017)}

CUESTIÓN.- Si el cese del funcionario interino nombrado por sustitución puede producirse con ocasión a la ocupación de la plaza por un funcionario de carrera distinto al sustituido. Identificar como normas jurídicas que, en principio, han de ser objeto de interpretación, las contenidas en el artículo 10, 9.1 y 91 del Estatuto Básico del Empleado Público (Real Decreto Legislativo 5/2015, de 30 de octubre).

FUNDAMENTO.- Cabe decir que en sentencia dictada el día 24 de septiembre de 2019 (recurso de casación número 1668/2017) por esta misma Sala y sección el día se fijo la siguiente doctrina: «el artículo 9.4 del Estatuto Marco no autoriza a la Administración a cesar al personal estatutario sustituto cuando no se ha reincorporado el titular del puesto de trabajo ni ha perdido el derecho a hacerlo.».

DOCTRINA.- Que el cese de un funcionario interino debe vincularse a alguna de las circunstancias expresamente contempladas en la norma de aplicación y, particularmente, el cese funcionario interino nombrado por sustitución de un funcionario de carrera con reserva de plaza o puesto solo debe producirse con ocasión de la ocupación efectiva de la plaza o puesto por el funcionario de carrera sustituido o por otro funcionario de carrera para el caso de que el titular inicial pierda el derecho a la reserva del puesto de trabajo y se realice una convocatoria al efecto o existe un mecanismo legal de adjudicación.. 